\title{
Container neophobia as a predictor of preference for earned food by rats*
}

\author{
DENIS MITCHELL, KIPLING D. WILLIAMS, and JULI SUTTER \\ University of Washington, Seattle, Washington 98195
}

\begin{abstract}
In a counterbalanced design, 16 rats were alternately tested for container neophobia and preference for earned food. Testing for earned food preference was conducted after three exposures to the free food source followed by seven exposures to the earned food source in an operant conditioning chamber. Testing for container neophobia was conducted in home cages after 21 sessions of habituation to a familiar container. There was a significant positive correlation between preference for earned food and container neophobia.
\end{abstract}

A number of researchers have reported that under certain conditions, rats will press a lever for food in the presence of free food (see D'Amato, 1974, for a review). Some authors (Carder \& Berkowitz, 1970; Jensen, 1963; Singh, 1970) have suggested that rats have a "preference" for earned food, while others (Atnip \& Hothersall, 1973; Taylor, 1972) have found that "preference" for earned food is limited to a small subset of the rat population. These latter authors suggest that though rats generally do not prefer earned to free food, the question as to why some rats will continue to leverpress for food when identical food, requiring less effort, is available has yet to be answered. Recently, Mitchell, Scott, and Williams (1973) suggested that neophobia is the essential factor generating a propensity for earned food in rats. In this view, it is not the method of procurement, as suggested by previous authors (Carder \& Berkowitz, 1970; Davidson, 1971; Jensen, 1963), but rather the animal's familiarity with the different food sources that determines its behavior in the earned food paradigm. The present experiment examines this relationship between a rat's neophobic avoidance of a novel food source and its preference for earned food.

\section{METHOD}

\section{Subjects}

Sixteen naive male Long-Evans rats, approximately 210 days old, served as Ss. All Ss were individually housed in 24 x $17.4 \mathrm{x}$ $18.5 \mathrm{~cm}$ stainless steel cages with water freely available.

\footnotetext{
Apparatus

For the portion of the experiment dealing with earned food preference, two identical operant conditioning chambers more fully described by Mitchell et al (1973) were used. Briefly, the chambers were enclosed in two separate sound-attenuating enclosures and dispensed earned food into a brass hopper by

*This research was supported by National Science Foundation Grant GB-40314 awarded to Robert C. Bolles, whom we thank for his support. We also thank D. Winfield Scott for his technical assistance and Stephen C. Woods and Ron Sigmundi for their helpful comments on the manuscript. Requests for reprints should be addressed to Denis Mitchell, Department of Psychology, University of Washington, Seattle, Washington 98195. This paper was sponsored by Stephen C. Woods, who takes full editorial responsibility for its contents.
}

means of a response lever requiring a force of $0.20 \mathrm{~g}$ to operate. One-way mirrors permitted unobtrusive viewing of $\mathrm{Ss}$ in the chambers. Both free and earned food consisted of 0.045-g Noyes pellets. Earned pellets were provided on a continuous reinforcement schedule. Free pellets were provided in a glass dish $(6.5 \mathrm{~cm}$ in diam and $1.5 \mathrm{~cm}$ deep $)$. The dish always contained 300 pellets when introduced into the chamber.

For the portion of the experiment dealing with container neophobia, two different food containers were used. One was a round white glass dish $(5 \mathrm{~cm}$ in diam and $2.5 \mathrm{~cm}$ deep); the other was a square stainless steel dish $(6.0 \mathrm{~cm}$ on a side and $1.5 \mathrm{~cm}$ deep). Both containers were filled with approximately the same quantity $(42 \mathrm{~g})$ of wet mash. The wet mash consisted of one part finely ground Purina Rat Chow mixed with two parts tap water. This formula reduced spillage to a minimum and facilitated consumption within the allotted time.

\section{Procedure}

Earned Food Preference. All Ss were given four daily magazine and barpress training sessions. During these preliminary training sessions, time in the apparatus was adjusted so that each $S$ completed a total of 140 reinforced responses over the 4-day period. After completion of preliminary training, Ss were given 3 consecutive days of free food sessions followed by 7 consecutive days of earned food sessions. During free food sessions, Ss were placed in the experimental chamber with the lever connected to a counter but disconnected from the pellet dispenser. The glass dish containing the free pellets was placed against the back wall opposite the food magazine prior to the introduction of the $S$. During the earned food sessions, the free food dish was removed from the chamber and the lever was connected to the pellet dispenser. All training and testing sessions lasted $40 \mathrm{~min}$. A given $\mathrm{S}$ was always fed from the same dish and trained and tested in the same chamber. Half of the Ss were run in one chamber, half in the other. After each daily session, Ss were returned to their home cages and given $10 \mathrm{~g}$ g standard size Purina rat pellets.

Testing for earned food preference consisted of placing the Ss in the experimental chamber with the free food dish removed and the response lever connected to the pellet dispenser. After the rat made 40 rewarded leverpresses, the blower, lights, and food dispenser were turned off; the chamber was opened, and the free food container was placed against the back wall of the chamber. The door was then closed and the power turned back on (after Jensen, 1963). The number of barpresses made after the dish of free pellets was placed in the chamber was recorded, as was free food consumption.

Container Neophobia. For 21 days, Ss were fed for $45 \mathrm{~min}$ once a day in their home cage. Half of the Ss were fed from the round glass container and the other half from the square stainless steel container. Ss were weighed every 4 days, and if their weight fell below $95 \%$ of their free feeding weight, they were given 
supplemental pellets. The test for novel container avoidance was conducted on Day 22 when a novel container was introduced in addition to the familiar container. For each half of the Ss, the novel container was identical to that used as the familiar container for the other half. When a single container was used, it was placed in the center of the front of the cage. When two containers were used, they were placed side by side in the front of the cage. For even-numbered Ss, the novel container was placed on the left; for odd-numbered Ss, it was placed on the right. The amount consumed from each container was calculated by weighing the portion remaining plus spillage and subtracting from the total originally presented.

The experiment was conducted in two parts. Half of the Ss were first tested in the earned food paradigm and later in the container neophobia procedure; the other half were tested in the reverse order. The different portions of the experiment were conducted under blind conditions; the $\mathrm{E}$ recording the earned food preference scores had no knowledge of novel container avoidance performance, nor was the $\mathrm{E}$ collecting the container neophobia data aware of the Ss' earned food preferences.

\section{RESULTS}

The results of both portions of the experiment are presented in Table 1. As indicated, all Ss avoided the novel container during container neophobia testing, but some Ss avoided it less than others $(\mathrm{t}=2.99, \mathrm{p}<.01$, two-tailed). Though the present results do not indicate that rats prefer earned to free food $(\mathrm{t}=.130$, n.s., two-tailed), all but two of the Ss made some responses for earned food in the presence of identical free food. Ss were ranked for both earned food and familiar container preference. A Spearman's correlation between the ranks revealed a significant positive correlation between the two measures $\left(r_{s}=.638, p<.02\right.$, two-tailed $)$.

Table 1

Test Session Data

\begin{tabular}{|c|c|c|c|c|}
\hline \multirow[b]{3}{*}{$S$} & \multicolumn{2}{|c|}{$\begin{array}{c}\text { Earned } \\
\text { Food Test }\end{array}$} & \multicolumn{2}{|c|}{$\begin{array}{c}\text { Container } \\
\text { Neophobia Test }\end{array}$} \\
\hline & \multicolumn{2}{|c|}{$\begin{array}{c}\text { Pellet } \\
\text { Consumption (no.) }\end{array}$} & \multicolumn{2}{|c|}{$\begin{array}{c}\text { Mash } \\
\text { Consumption (g) }\end{array}$} \\
\hline & Earned & Free & Familiar & Novel \\
\hline 1 & 14 & 241 & 13 & 6 \\
\hline 2 & 0 & 240 & 18 & 13 \\
\hline 3 & 10 & 287 & 31 & 3 \\
\hline 4 & 286 & 2 & 34 & 0 \\
\hline 5 & 260 & 40 & 36 & 1 \\
\hline 6 & 49 & 244 & 29 & 1 \\
\hline 7 & 107 & 64 & 37 & 2 \\
\hline 8 & 0 & 145 & 27 & 7 \\
\hline 9 & 210 & 67 & 18 & 8 \\
\hline 10 & 219 & 3 & 26 & 6 \\
\hline 11 & 46 & 98 & 27 & 10 \\
\hline 12 & 80 & 152 & 39 & 3 \\
\hline 13 & 21 & 211 & 18 & 11 \\
\hline 14 & 207 & 18 & 34 & 0 \\
\hline 15 & 94 & 137 & 23 & 7 \\
\hline 16 & 241 & 6 & 36 & 2 \\
\hline Mean & 115.2 & 122.2 & 27.9 & 5.0 \\
\hline
\end{tabular}

Observations of the Ss during testing for earned food preference revealed that most Ss initially spent most of their time eating the free food. Several authors (Davidson, 1971; Mitchell et al, 1973; Taylor, 1972) have also noted this initial consumption from the free food dish followed by a shift to the earned food source later in the test session. An additional observation, also reported by Carder and Berkowitz (1970), was that several of the rats moved the free food container from its original position against the back wall of the chamber to the front of the chamber nearer the bar and hopper during the earned food preference test.

\section{DISCUSSION}

The present results suggest that a considerable portion of the earned food preference in rats is related to their preference for the more familiar of two food sources. Further, these results are consistent with the view that the two food sources available in the earned food paradigm, although offering identical food, are not perceived as identical by the rats (D'Amato, 1974). Both the present results and those of Mitchell et al (1973) indicate that the relative novelty of the two food sources is of crucial importance in this paradigm.

This view is further supported by the behavior of the animals during testing. The inclination of several of the rats to move the free food container nearer the more familiar eating place has its counterpart in the hoarding literature. Bindra (1948) reported that one of the primary determinants of hoarding in rats is the relative novelty of the different components in the hoarding situation. Generally, his Ss moved the food offered them to the most famliar portion of the apparatus before feeding.

As previously discussed, several authors have also observed that the probability of the rat leverpressing greatly increases with the passage of time in the test session (Davidson, 1971; Mitchell et al, 1973; Taylor, 1972). Bolles (1962) reported that readiness to eat in a novel situation is a function of deprivation conditions; the more deprived a rat, the sooner it begins feeding in a novel situation. Similarly, the general finding that there is an initial preference for free food followed by a shift to earned food could be viewed as simply an initial willingness to eat from a novel food source followed by an increasing reluctance to do so as the animal becomes satiated. In a sense, deprivation mitigates neophobia; the more deprived a rat, the less neophobic it is likely to be.

That the rats in the present experiment showed a greater avoidance of the novel container in their home cage than they did of the free food source in the earned food paradigm was probably due, in part, to the greater habituation to the familiar container in the container neophobia test than to the earned food source in the earned food paradigm and, in part, to their prior experience with the free food dish in the earned food paradigm. This observation is consistent with a large body of data (see Welker, 1961, for a review) which indicates that whether a given stimulus elicits approach or avoidance from the rat depends on the degree of habituation to both the stimulus and to the situation in which the stimulus is presented.

\section{REFERENCES}

Atnip, G., \& Hothersall, D. The preference of albino rats for free or response-produced food. Bulletin of the Psychonomic Society, 1973, 3, 153-154.

Bindra, D. The nature of motivation for hoarding food. Journal of Comparative \& Physiological Psychology, 1948, 41, 211-218.

Bolles, $R$. C. The readiness to eat and drink: The effect of 
deprivation conditions. Journal of Comparative \& Physiological Psychology, 1962, 55, 230-234.

Carder, B. \& Berkowitz, K. R at's preference for earned in comparison with free food. Science, 1970, 167, 1273-1274.

D'Amato, M. R. Derived motives. Annual Review of Psychology, $1974,25,8-106$.

Davidson, A. B. F actors affecting keypress responding by rats in the presence of free food. Psychonomic Science, 1971, 24, 135-137.

Jensen, G. D. Preference for bar pressing over "freeloading" as a function of number of rewarded presses. Journal of Experimental Psychology, 1963, 65, 451-454.

Mitchell, D., Scott, D. W., \& Williams, K. D. Container neophobia and the rat's preference for earned food. Behavioral Biology, 1973, 9, 613-624.

Singh, D. Preference for bar pressing to obtain reward over freeloading in rats and children. Journal of Comparative \& Physiological Psychology, 1970, 73, 320-327.

Taylor, G. T. A limitation of the contrafreeloading phenomenon. Psychonomic Science, 1972, 29, 173-174.

Welker, W. J. An analysis of exploratory and play behavior in animals. In D. W. Fiske and S. R. Maddi (Eds.), Functions of varied experience. Homewood, Ill: Dorsey Press, 1961.

(Received for publication May 30, 1974.) 